This is a self-archived version of an original article. This version may differ from the original in pagination and typographic details.

Author(s): Ursin, Jani; Aittola, Helena

Title: 'It's Not Like Everything Changes Just With a Click on New Year's Eve' : Perceptions on Educational Issues of University Mergers in Finland

Year: 2021

Version: Accepted version (Final draft)

Copyright: (c) 2019 International Association of Universities

Rights: In Copyright

Rights url: http://rightsstatements.org/page//nC/1.0/?language=en

Please cite the original version:

Ursin, J., \& Aittola, H. (2021). 'It's Not Like Everything Changes Just With a Click on New Year's Eve' : Perceptions on Educational Issues of University Mergers in Finland. Higher Education Policy, 34(3), 543-559. https://doi.org/10.1057/s41307-019-00151-3 
'It's not like everything changes just with a click on New Year's Eve': Perceptions on educational issues of university mergers in Finland Jani Ursin ${ }^{\mathrm{a} *} \&$ Helena Aittola ${ }^{\mathrm{a}}$

${ }^{a}$ Finnish Institute for Educational Research, University of Jyväskylä, Finland

*Jani Ursin, jani.p.ursin@jyu.fi, Finnish Institute for Educational Research, P.O. BOX 35, FI-40014 University of Jyväskylä, Finland, tel. +358 503030811 ORCID 00000001-6557-9058

Helena Aittola, helena.s.aittola@jyu.fi, Finnish Institute for Educational Research, P.O. BOX 35, FI-40014 University of Jyväskylä, Finland, tel. +358 408054243 ORCID 0000-0002-1883-7621 


\title{
'It's not like everything changes just with a click on New Year's Eve': Perceptions on educational issues of university mergers in Finland
}

\begin{abstract}
The study explored educational perceptions concerning Finnish university mergers. The data were collected by interviewing academics and students $(\mathrm{n}=$ 30) in four merger projects. Qualitative content analysis was applied to the data. According to the findings, (i) the implications of the merger with regard to educational activities were primarily connected to the institutions' own culture and history; (ii) new openings in education, teaching, and learning were only moderate in scope at the time of the interviews; (iii) there is strong potential for the enhancement of teachers' pedagogical competence; (iv) creating a joint organisational and educational culture is a challenging and time-consuming task. The findings further suggest that it is important to pay attention to openness and transparency at all stages of a merger. The study highlights the fact that the actual changes in education, teaching, and learning are slow.
\end{abstract}

Keywords: academics; education; merger; reform; university

\section{Introduction}

Global competition in higher education has prompted reconstruction of national higher education systems, often because the long-established ways of coordinating research and teaching in higher education institutions are considered inadequate and outdated (Mathisen and Pinheiro, 2016). In order to secure their wider survival, universities have been expected to adapt to wider environmental changes (Pinheiro and Stensaker, 2014) by reinforcing their profiles and strategies through institutional mergers (Melin, 2015).

In Finland, from the mid-2000s onwards, the government has instigated a series of reforms, branded as 'the structural development of the Finnish higher education system'. The goals have included expansion of the funding base of universities, increases in cooperation with foreign (top class) universities, plus ensuring the quality 
and effectiveness of university-based research and teaching activities (Opetusministeriö, 2008). The two main consequences of the reforms have been, firstly, university mergers to decrease the number of higher education institutions, and secondly, the New Universities Act, which separated universities from the state budget (Välimaa, 2012).

Most previous studies on the mergers of higher education institutions have focused on organizational, managerial, and governance aspects, with less attention to how a merger impacts on educational issues. Hence, the aim of this study was to explore the educational issues involved in implementing Finnish university mergers. The data consisted of semi-structured interviews $(n=30)$ with academics - including those in leader and administrative positions - and also with students, i.e. a group whose perspective is often neglected yet important (Hay et al., 2001). The context was that of four different mergers between Finnish universities. The data were analysed by means of content analysis. The paper is structured so that at first we introduce previous studies on the mergers of higher education institutions, then explain the aims and methods of our study, after which we present the findings, and finally end the paper with discussion and conclusions.

\section{Background}

In many countries, state or governmental control over universities has weakened, with universities being given more autonomy. This has meant latitude for universities, who seek to manage their organizational, financial, and administrative assignments more efficiently, while successfully carrying out their basic missions in research and education (De Boer and Jongbloed, 2012). Mergers are thus often seen as an adaptive reaction to a changed environment.

One of the most common anticipated benefits from university mergers is that decreasing the number of institutions will lower the financial costs of maintaining the 
higher education system. In conjunction with this, it is hoped that mergers will facilitate the recruitment from abroad of skilled faculty and students, by providing them with attractive environments to work and study. At the individual university level, these internationally-oriented aims are accompanied by awareness of a need to renew management procedures, and to cut down administrative costs (Aarrevaara et al., 2009).

Despite similarities in general aims, there has been wide variation in the merger processes. In some cases, mergers have been initiated mainly by the universities themselves (voluntary mergers), whereas in other cases the mergers have been imposed by the government (involuntary mergers). In practice, purely voluntary mergers scarcely exist, since many voluntary mergers have been stimulated via the financial incentives provided by the state (Harman and Harman, 2003).

A successful merger of higher education institutions requires solid leadership, (e.g., Livio and Tomperi, 2011), competent management of the university (Kyvik, 2002), transparent communication between all parties involved (e.g. Stensaker et al., 2016), plus clear strategies, branding, and human resource systems (Tienari et al., 2016). Altogether, building a new collective organizational culture is a demanding and lengthy task, so that discussions on a new institutional identity and a sense of belonging form an imperative and indispensable part of a merger (Calma and Davies, 2015; Harman and Harman, 2003; Kyvik, 2002; Ursin, 2017). Furthermore, mergers are complex and burdensome undertakings for the institutions and staff alike (Cartwright $e t$ al., 2007), influencing how staff perceive their academic (Ylijoki and Ursin, 2013) and organizational (Puusa and Kekäle, 2015) identities. However, academics are not a uniform group, as the management and employees of the universities often have different views on both the processes and the outcomes of a merger (Aagaard et al., 2016). Consequently, Cai and colleagues (2016) conclude in their conceptual 
framework of the merger process that a merger is affected by a number of factors such as those related to environment, economic benefits, institutional compatibility and human agency.

As mentioned above, most previous studies on the mergers of higher education institutions have focused on organizational, managerial, and governance aspects, with less attention to how a merger impacts on educational issues. This can be partly explained by the fact that curricular matters are typically under the control of faculties, with teaching traditionally tending to be 'solitary and less responsive to collaborative efforts' (Stein and Short, 2001). There is some evidence that at the institutional level, the need for mergers can originate from organizational demands to guarantee highquality education with concentrated resources on the one hand, and to avoid educational overlaps on the other. Furthermore, amalgamations can afford new possibilities to organize education and training (Mathieson, 2012; Ursin et al., 2010; Vartiainen, 2017). Williams (2017) has summarized the possible benefits of mergers to teaching and learning, noting that mergers can:

- expand course and programme offerings, allow specialization in areas of strength, create new student pathways, and support new modes of delivery;

- permit institutions across binary divisions to combine distinctive and complementary strengths of professionally-oriented and theoretical instruction;

- allow individual professors to focus on instruction in their areas of greatest strength;

- pool resources (financial, technical, and other) for supporting new modes of instruction;

- generate efficiencies through the elimination of redundant programmes and courses; 
- encourage more transparent academic recognition procedures.

\section{The aims and methods of the study}

The aim of this study was to explore educational issues relating to Finnish university mergers, as perceived by academics (including those in managerial positions) and students. The research questions were as follows:

(1) What are the main needs and aims for educational cooperation between the merging universities?

(2) How do people perceive the implementation of the merger with respect to educational issues?

(3) What are the main challenges and opportunities of the mergers in regard of educational issues?

This study focuses on all the four original merger projects in the university sector which were funded by the Finnish Government (for more detailed information, see Ursin et al., 2010):

(1) Aalto University: Helsinki University of Technology + Helsinki School of Economics + University of Art and Design, Helsinki;

(2) University of Eastern Finland: University of Joensuu + University of Kuopio;

(3) University of Turku: Turku School of Economics + University of Turku;

(4) University Alliance Finland: Tampere University of Technology + University of Tampere + University of Jyväskylä.

The first three new universities came into being officially at the start of 2010 . The fourth case remained a very loose alliance, and never led to an actual merger. 
The overall merger processes consisted of different phases, which varied across the cases above. Our own focus was on the implementation phase of the mergers. The data were collected in the spring of 2009 by face-to-face interviews with management personnel, teachers, and students from each university. There were 30 interviews in total (all interviews were carried out in Finnish), and they included 7-8 interviewees from each person category (i.e. managerial staff, teachers, students). To elicit relevant knowledge concerning the mergers, the interviewees were selected from academics and students who already had experience of the merger process, for example, as members of committees and working groups, planning managers, or coordinators of research and teaching.

The interviews were semi-structured in format and they encompassed the following main themes as viewed by academics and students: the basis and aims of cooperation in the mergers; the organization and modes of educational cooperation; new pedagogical practices, challenges and opportunities; and future prospects.

The interviews lasted 45-50 minutes on average, and were recorded and transcribed (resulting in 469 pages of transcript). The interview data were analysed by qualitative content analysis, so that initially, similar notions were coded under preliminary content categories, and subsequently final categories were formed on the basis of relational analysis in which the categories that were similar to all four mergers were combined and further elaborated based on the four data sets as well as on a relevant conceptual framework (Braun and Clarke, 2006). In the analytical process, ATLAS.ti software was deployed to condense and display data. Extracts from the interviews are used in this article (block quotations, indented) to illustrate the key elements of each category. The number after each extract is the code given to the 
interview. For the sake of anonymity, it is not possible to provide more detailed information on the interviewees.

\section{Results of the study}

In the interviews, the following main themes with respect to the merger were emphasized: needs and aims relating to educational cooperation, the implementation of the merger, and the challenges and opportunities in the merger. Below we consider these themes in more detail.

\section{Perceived needs and aims relating to educational cooperation}

The interviewees saw a need for educational cooperation stemming from both external demands and internal needs (see Table 1). On the whole, the external demands were connected to the changes taking place in higher education policy. The trend towards the internationalization of all academic activities was seen as necessary in this context. In this the interviewees included, for example, an efficient international recruitment policy to reach the most prominent researchers, and the most promising students:

\footnotetext{
In fact it [internationalization] is one of the driving forces of this change. So that we must be able to compete in the international market for students and the workforce, because these national resources won't - we have good people here but not enough to maintain so many universities. So if we want to truly compete globally in order to have top-level universities in Finland, we just have to get staff from abroad, and students as well. So in a way the days of national universities are now over. (administrator/leadership, 30)
}

The need to improve the quality of teaching and learning was stressed by the interviewees, especially in accordance with the principles of the Bologna process. The interviewees mentioned that the merging of universities, with their unique educational 
profiles, can provide study programmes that are highly valued internationally:

When we talk about improving quality, we see it as having two aspects. On the one hand we see it as being able to raise the quality of our administration and services, because we'll have greater resources to provide support services for teaching, for instance, or services pertaining to guidance or services related to the commercialization of research. The product quality aspect, in particular, will be improved. Then again, when we look at the quality of research or the quality of teaching, these matters of substance, these core processes, the fact is simply that when we can direct resources to certain targets by strategic measures, the quality will definitely improve. It's just inevitable. (administrator/leadership, 3)

Globally, efforts to achieve competitiveness are increasing, as universities aim to be world-class players. This became evident in our study as well. According to the interviewees, merged (and thereby larger) universities are considered to be in a better position to compete for resources, staff, students, and partners than smaller ones. Hence, the larger size of the new university was seen as an essential competitive asset in the educational market. However, the efforts towards better rankings and ratings in the global market were also perceived critically by the interviewees:

This stems from those particular OECD reports, which give Finland a certain bad reputation. The fact is that the purpose of this [merger] is partly also to make the statistics look better, so that Finland would reach a better ranking in certain statistics - these were primarily the pressures. These are by no means due to the universities' operational needs - the pressure has come from outside. (academics, 20)

The interviewees also stressed the importance of the Ministry of Education and Culture initiating and funding a merger:

The bang [i.e. opening shot] came from the Ministry of Education when it set out with this structural development scheme, but my personal opinion was that this whole thing was in such a state that it would have been unavoidable in any case. [It 
was] like this metaphor I used somewhere, the gun was actually loaded a long time ago, so that the structural development programme launched by the Ministry of Education provided just the necessary final squeeze. And I myself think that the people in the Ministry are not stupid - there just was at this point sufficient political will, so that we got this thing going. (administrator/leadership, 2)

Table 1. External and internal reasons for educational cooperation (number of references in brackets)

\begin{tabular}{|l|c|}
\hline External (73) & Internal (89) \\
\hline Internationalization (20) & Rationalization of activities (70) \\
Improvement of quality (17) & Clarification of the profiles and \\
Increase in competitiveness (15) & enhancement of activities (53) \\
Demand from the government (12) & - Appropriate use of resources (10) \\
& - Facilitation of synergies (7) \\
& Development of education (19) \\
\hline
\end{tabular}

The interviewees perceived that the internal reasons for cooperation stemmed mainly from a need to rationalize university activities, not only in administration, but also in education and in research (see Table 1). Rationalization was related to clarifying the distinctive profiles of the merging universities, and to enhancing their activities. The interviewees felt that because the profiles are built on the universities' prevailing strengths, it was anticipated that after the merger the new universities could be more powerful actors in the (inter)national educational market. One interviewee from Aalto University elaborated this point as follows:

[We are] profiling ourselves in terms of combining the strengths of the three domains. That is, we have business studies, technological sciences, and these arts and design subjects, which we hope will stimulate innovative activities in particular. So this profiling is the particular key issue in our case, so that we're not aiming to develop ourselves into a sort of a rival, for example, to the University of Helsinki in all areas of basic research (administrator/leadership, 30)

Another form of rationalization mentioned by the interviewees had to do with resources. 
The interviewees saw achieving economic gains as one prime rationale behind a merger.

Although a merger could call for vast investments and resources at the outset, the interviewees believed that resources could be used more effectively, and that enhanced cooperation between the merging institutions would bring significant synergy benefits in the long run:

On the other hand, as we're increasingly living amidst global competition, including the higher education sector, we need to use and take advantage of resources as efficiently and effectively as possible. And because it's impossible for everyone to do everything, it is relevant to discuss if we could accomplish more by joining forces. Moreover, we have scarce financial resources, although not in the sense that when you follow debates in university circles, you get the impression that the funds have been just decreasing all the time - which is not true. On the contrary, they have grown, but not in proportion to the growing needs. (administrator/leadership, 16)

As illustrated above, the interviewees did associate the third form of rationalization with synergy benefits. The interviewees emphasized that instead of competition, it makes more sense to look for synergies, so that the merging universities' educational and research structures, and overall profiles, will support each other:

On the other hand, we also wanted to get these two universities genuinely together, so that there is no rivalry between us in education and research. We can now look at our partly overlapping educational structures and partly overlapping research structures and research studies. We adopted two approaches to achieve this, and through it, the benefits will emerge - and have already emerged, genuinely. (administrator/leadership, 3)

In terms of the development of educational activities, the interviewees felt that a merger can provide many advantages, especially for students. Merged universities can organize more diversified study programmes and broaden the range of subjects available to students. This is likely to encourage students to choose different subjects and courses, 
leading to novel subject combinations for university graduates. One of the students interviewed described this in the following way:

Well, it is important, at least in the sense of whether it [the merger] appears to the students [to be such] that a student can choose his studies in a different way and specialize in different ways. And in a way form new kinds of combinations and thereby improve his position in the labour market. (students, 8)

Furthermore, the interviewees hoped that a merger would retain and, if possible, further solidify the relationship between research and teaching:

Well I think that the new trend will actually be teachers doing research here in the university. So, we have at least had possibilities, quite good ones in my opinion, in these subjects in our faculty, people have been able to organize for themselves time for research where it's needed, and it actually shows in the quality of the teaching, too. So I mean that I wouldn't see that this type of cooperation, either, would lessen the value given to research, in fact quite the contrary. And regarding the sort of discussions I've been involved in, it has been mostly about people wanting even more research, including from the teaching staff. (academics, 13)

There were critical voices as well. Some interviewees raised a concern that in the merger, research and teaching could easily be placed in opposition to each other:

Often, perhaps rather unintentionally, these things [research and teaching] are set somewhat in opposition to each other. It is not very holistic academic thinking. (administrator/leadership, 15)

\section{Perceptions of the implementation of a merger}

The interviewees pointed out that the implementation of a merger is inherently a long and complex process. Various committees and working groups had been set up to plan and implement the changes. Typically, these groups had representatives from among both staff and students. The interviewees highlighted the following aspects (number of references in brackets): 
- Communication (45)

- Novel pedagogical models (39)

- New responsibilities and opportunities for staff and students (34)

- Cultural factors (34)

According to the interviewees, it is essential to have effective communication strategies to keep staff and students informed at every step of the merger process. From the interviews, it appeared that the communication practices differed considerably between the merging universities: People might not always have continuous access to relevant information concerning the merger process. Furthermore, there had been variation in the opportunities to participate in the planning process, depending on the positions of those concerned. This applied to both staff and students. According to the interviews staff and students who had been actively involved in various working groups perceived a relatively strong connection with the information provided. Other groups and individuals had no such perception:

Well I think, for example, that with us, thinking of assistants and senior assistants, for instance, they don't know anything about this sort of thing, I guess. We actually do have information shared all the time, by email I mean, but I suspect that the topic is so uninteresting - so that for many it's a bit like, still like a joke even 'What do you mean, what alliance?' (academics, 13)

One positive theme that emerged in the universities was improvement in the status of teaching. There were many comments on how pedagogical training had the potential to improve teachers' and researchers' pedagogical expertise. The interviewees believed that pedagogical qualifications would have a stronger emphasis in recruitment policy in the near future, with pedagogical studies becoming a formal requirement for entry to university teaching posts: 
There's this kind of a concrete thing that one of our projects is a project on the teaching of university pedagogy. The idea there is that through this consortium project, funded pedagogical training will be offered to the teachers in both universities, up to 60 study credits. (administrator/leadership, 6)

According to the interviewees, merged institutions can provide new and innovative pedagogical models. This could mean, for example, that the teaching will become more interactive and student-centred. The interviewees considered that the forthcoming joint courses and multidisciplinary study programmes had the potential to improve teamwork skills among teachers and students. The geographical distances between the campuses involved in the merger will require new solutions with regard to teaching arrangements. Hence, new ICT-based teaching arrangements will have a crucial role in this new educational setting:
We have also set out to build something quite novel, raising online teaching and related activities to a new level, both in terms of our equipment, and also how the teachers cope with and manage the whole of it. You know, we have this big challenge, that when we have Kuopio-Joensuu, we will also have Savonlinna. We have this idea that we can genuinely cover [the teaching], so that in joint Bachelor programmes, for instance, the teaching can be arranged so that it will be [available] if we have students also in Savonlinna. We could perhaps make it so that the teacher wouldn't need to go and give the same course in each of the three places, and that it could be given by means of modern online methods and video conferencing. (administrator/leadership, 3)

The interviewees considered that the academic staff's job descriptions and the students' roles would change as a result of merger-related processes. The clarification of new university profiles will make it easier to utilize the potential of teaching staff and further increase their commitment to teaching. The interviewees highlighted that in the construction of a new institutional identity, what is most needed from university staff is open-mindedness and adaptability to continuous changes. Ideally, in merged 
universities, students will be able to choose their courses and study programmes more freely, which further underlines their responsibility for their own studies and their learning processes. Thus, learning has a potential to become more student-centred:

A striking feature that you notice there abroad, from what I've seen, is that they have terribly long working hours and spend time with the students. It's not at all like you come to give a two-hour lecture and stop it abruptly in mid-sentence, to be continued next morning at 08:15 (academics, 10)

According to the interviews, on the whole, in a university merger the creation of a joint organizational, teaching, and learning culture constitutes a demanding task for the institutions involved. However, the interviewees felt that the aim is not to abolish the unique character of the merging institutions, but rather to retain some of the distinct cultural aspects of the institutions, in order to enrich the new entity. The interviewees pointed out that the establishment of cultural changes is a long-lasting process, and that it cannot be steered in a top-down manner. Creating a joint culture can be challenging:

The issue of creating a joint culture, it's truly a huge one - I don't know if it will require new people to step in to some degree, a new generation. It can be set up on paper all right, and to some extent people have started to realize the fact, I guess, that from the beginning the next year they will be employees of the University of Eastern Finland. But then, the issue of achieving the joint culture and shared practices - it is now under a lot of discussion. (administrator/leadership, 19)

\section{Perceived merger-related challenges and possibilities for educational issues}

The interviewees saw various challenges and opportunities related to a university merger. A wide range of issues were raised in this regard (Table 2). Naturally, the interviewees were worried about the continuation and sufficiency of resources in a changing situation. The principles for the allocation of resources between different institutions were far from clear, and this fed feelings of uncertainty among the 
interviewees. Furthermore, the implementation process had been mainly based on the staff's contribution, thus adding to their daily workload. Because the basic structures of teaching were changing, the interviewees were also worried about their own working conditions. The interviewees saw that there was a risk that joint courses would increase the number of students in one institution, involving more lecturing as the mode of teaching - for obvious practical reasons - and difficulties in setting up more studentcentred teaching methods. At worst, the merger might lead to retrenchment, so that departments would be forced to reduce their courses and teaching jobs. One of the interviewees commented on the increased workload as follows:

Undoubtedly these kinds of processes, when these are first introduced - given that people already have fairly heavy workloads - now these bring extra work, so I do understand that people now also oppose it. (administrator/leadership, 2)

Some interviewees were firmly set against the merger as a whole, and they expressed strong resistance to the changes. As they saw it, the whole process could be labelled as 'quasi-merging', meaning that only the administrative structures would change, without any concrete transformations in academic activities:

It is not necessarily for anyone's benefit, either, that it's as if we were creating a sort of administrative merger but not any concrete merger. Indeed, a risk here is, in a way, that it will just mess things up, that it won't be a good thing, that it will just bring confusion. It won't be a good thing then but a bad one, because in fact it might have been better if these had really remained two separate units. (students, 26)

According to the interviews, there were educational challenges, and especially a risk that joint courses would increase the number of students in a given institution. As noted above, this could involve more lecturing as a mode of teaching and fewer studentcentred teaching methods: 
So, one of the challenges is that the group sizes are too large for the kind of learning and teaching I find appropriate for an applied science. So I don't know how useful it is to teach large crowds by some kind of lecturing, as we have to do now there in my course, for example. (academics, 25)

The interviewees saw the geographical distance between the universities to be merged as a demanding challenge for educational arrangements. This was especially the case with the participants from the University of Eastern Finland:
Anyway I'm a bit sceptical, as I watched it there in one polytechnic, when people tried to arrange teaching together, so that there were students in Lahti and then here in Tampere, and it was of rather poor quality. Although the lecturers were commuting then - but those who were always at the end of a video connection, for example, were clearly disadvantaged. (students, 8)

The interviewees also found some invisible barriers to merging in the form of inflexible work patterns. Individual institutions might have been so accustomed to their own administrative practices that any increase in cooperation was hampered to some extent. For this reason, some interviewees considered the merger to be merely adding bureaucracy:

\footnotetext{
In a way I find that the biggest challenge is, putting it in business language, that we can ask what the added value of this [merger] is. In our opinion, we're both doing good work already, and have full workloads - Will this bring a further load? Is this like 'yet another form of bureaucracy'? Or what are you offering us? (academics, 11)
}

From the interviewees' point of view, the management of the changes as a whole has varied across the different institutions involved. Some interviewees perceived that the merger process has been steered too tightly, while others might argue that nobody really seemed to have any control over it: 
This [memo of a meeting], for instance, talks about duties, so it says there in the middle of the paper, [that it's] attached as an appendix to the decision, that certain people have been appointed to such-and-such a post. So it's not absolutely certain that everybody will read the papers. And there is no discussion or oral information whatsoever about the matters [that are to be dealt with] between the rectors and the deans. (academics, 22)

Table 2. Challenges and opportunities related to a university merger (number of references in brackets)

\begin{tabular}{|l|l|}
\hline Challenges (120) & Opportunities (60) \\
\hline Sufficiency of resources (35) & Improvement of basic activities (34) \\
Firmly-held opinions concerning the & More opportunities for novel study \\
reality of change (27) & arrangements (18) \\
Educational challenges (20) & More flexibility in the use of resources \\
Distances between campuses (17) & $(8)$ \\
Inflexibility of work patterns (11) & \\
Management of change (10) & \\
\hline
\end{tabular}

Although merging was obviously a challenging process, it could bring along some advantages. The interviewees perceived that the merger of the institutions would influence all the basic functions of a university. Most importantly, the interviewees felt that it would create new opportunities for cooperation and collaboration in basic activities. To some extent, the implementation of structural changes can give a welcome boost to discussion and dialogue at all levels. In this way the interviewees felt that there was a chance to create a new 'we-spirit' within the merging universities:

For many issues, this will actually be not a revolution, but evolution, so that it's not like everything changes just with a click on New Year's Eve. So this job will certainly be under development for a decade, under construction. And the same as in many issues in the Aalto development, we can speak about the year 2020, you know, what we'll be like then. (academics, 4)

The interviewees were looking forward to the new study programmes and courses that might attract the best students. In this new educational context, the interviewees 
anticipated that student-centred teaching and learning methods will flourish, contributing to meaningful study processes and better learning outcomes:

And then the point that we would get a chance to build these learning and study environments in a really good way, to support learning much better than the present auditoriums do, just doling out information. So there could be some sort of greater changes there. (administrator/leadership, 9)

Some interviewees believed that various resource issues would be more easily resolved through a more flexible use of resources after the merger. They also anticipated that the merger and rationalization of administrative activities would eventually release extra resources for the main functions of the university, namely research and education. One of the interviewees expressed the following wish:

Of course, we hope that we'll also get more resources for teaching at some level. And how this will come about is linked to the reorganization of administration, and to the possibility that some resources might be directed or released from administration, which could then be allocated to teaching and research. (students, 26)

\section{Discussion and conclusions}

The study indicated that the objectives set by the Ministry of Education and Culture for the structural development of the higher education system steered the merger processes (see Opetusministeriö, 2008; Williams, 2017). From the point of view of institutional theory this indicates a balanced relationship between a merger process and external demands for a merger (see e.g., Cai et al., 2016).

The interviewees had high, perhaps not always realistic hopes towards mergers in relation to educational issues. The interviewees wished that staff and students would take maximum advantage of the new educational possibilities created through mergers 
(see Mathieson, 2012). However, the interviewees assumed that the changes in education would take root step by step. The informants also considered that the success of mergers would ultimately build upon how the new possibilities and ways of doing things were embraced, to what extent new pedagogical arrangements would be put into practice, how students could benefit from the range of possibilities, and how and to what extent administrative constraints would be abolished to make studying more flexible within and beyond the merged universities (see Vartiainen, 2017; Williams, 2017).

According to the interviewees, transparent communication and leadership as well as the creation of a joint organizational and educational culture was seen as crucial for the success of a merger (see Calma and Davies, 2015; Harman and Harman, 2003; Kyvik, 2002; Livio and Tomperi, 2011). In the framework of institutional theory, the interviewees thus highlighted the importance of agency; the fact that academics and students had a possibility to influence and actively participate in the merger (Cai et al., 2016).

In the light of the interviews, the main challenges in mergers were related to the sufficiency of resources, to addressing set opinions, and to managing geographical distances between campuses through utilizing the possibilities of ICT (cf. Kyvik, 2002). The interviewed academics and students considered that in the best scenario, the mergers could contribute to the formation of novel educational arrangements and procedures as well as offer broader possibilities for studying (see Calma and Davies, 2015; Williams, 2017). Nevertheless, the interviewees stressed that the actual changes in education, teaching and learning would be adopted fairly slowly, even if the structural framework changed more rapidly (see Mao et al., 2009). When it comes to favourable conditions, Cai and colleagues (2016) explain a successful creation of joint 
organization and educational culture by the compatibility between the cultures of premerger groups.

To conclude, according to the findings of this study, the following four aspects characterize the implementation phase of mergers in Finnish universities. These aspects are truly worth considering by those involved in - and especially those leading - a merger process in higher education.

First of all, the mergers bring a range of challenges and opportunities. It is true that the merger processes followed broadly similar paths in terms of their starting points and goals in different universities. However, as perceived by the interviewees, the issues and implications of the merger with regard to educational activities were mostly attached to the institutions' own culture and history. It is therefore understandable that the staff may have some firm opinions and doubts about the mergers (see Ylijoki and Ursin, 2013). Hence, there is reason to argue that the unique characters of individual universities should be taken into account in laying the foundations of a merger.

Secondly, up to now, new openings in education, teaching, and learning have been limited in scope. Overall, according to the interviews, there were relatively few educational innovations connected to the mergers. This can be partly explained by the nature of the administrative and organizational transformations, which have been so challenging and taken up resources to such a great extent that they have overridden attention to educational issues. There is also the point that radical reforms in education and teaching can easily trigger resistance among teaching staff, bearing in mind that such reforms can be disruptive to accustomed practices, and may even lead to axing some study programmes altogether (see Cartwright et al., 2007). However, a merger can also provide opportunities for successful re-evaluation and reorganization of education and teaching. 
Thirdly, generally speaking, it is important to enhance the pedagogical competence of teachers. Even though the educational openings were moderate in themselves, the pedagogical competence of teachers was emphasized in every merger. According to the interviews, the participating universities had already started to provide pedagogical training for their researchers and teachers, seeking thus to offer better instruction for the students. This creates a strong basis for improvement in the quality of education. It is essential to invest in the quality of training, since this manifests and brings into view the conceptions of learning and teaching embraced by the university, and determines the educational profile of the university.

Fourthly, in this study, the creation of a joint culture was found to be a highly important yet demanding. The interviewees stressed the pivotal role of well-functioning management and leadership as well as of transparent communication in forming a joint culture (see Livio and Tomperi, 2011). Nevertheless, some interviewees questioned the transparency of the merger process as conducted within their institutions. It is therefore important to pay more attention to the creation of a 'we-spirit' enabled and promoted by openness and transparency at all stages of a merger (see Stensaker et al., 2016; Ursin 2017).

Our study has certain limitations. The participants were individuals who already had some experience of the merger process. In this respect, we must recognize that the perceptions of mergers from the data here may not be fully generalizable elsewhere. Nonetheless, while perceptions of mergers are inevitably shaped within each specific context, locally anchored perceptions have their own relevance among the range of opinions voiced within discussions on the nature of mergers.

The study also provides avenues for future studies. The data for this study were collected at the time when Finland was undergoing the first round of university mergers. 
This was almost a decade ago. Hence, it would be useful to conduct a follow-up study on the present state of the mergers. Currently, Finnish higher education is experiencing a second generation of mergers, which includes mergers between different types of higher education institutions (universities and universities of applied sciences). It would also be relevant to compare the implementation of these second-generation mergers to the delivery of the first round of mergers, and to explore whether anything has actually been learned from the earlier cases.

\section{Disclosure statement}

No potential conflict of interest was reported by the authors.

\section{References}

Aagaard, K., Hansen, H. F. and Rasmussen, J. G. (2016) 'Mergers between governmental research institutes and Universities in the Danish HE sector', European Journal of Higher Education 6(1): 41-55.

Aarrevaara, T., Dobson, T. I. and Elander, C. (2009) 'Brave new world: Higher education reform in Finland', Higher Education Management and Policy 21(2): 1-18.

Braun, V., and Clarke, V. (2006) 'Using thematic analysis in psychology', Qualitative Research in Psychology 3(2): 77-101.

Cai, Y., Pinheiro, R., Geschwind, L. and Aarrevaara, T. (2016) 'Towards a novel conceptual framework for understanding mergers in higher education', European Journal of Higher Education 6(1): 7-24.

Calma, A. and Davies, M. (2015) 'Studies in higher education 1976-2013: a retrospective using citation network analysis', Studies in Higher Education 40(1): 4-21.

Cartwright, S., Tytherleigh, M. and Robertson, S. (2007) 'Are mergers always stressful? Some evidence from the higher education sector', European Journal of Work and Organizational Psychology 16(4): 456-478. 
De Boer, H., and Jongbloed, B. (2012) 'A Cross-National Comparison of Higher Education Markets in Western Europe, in A. Curaj et al. (eds.) European Higher Education at the Crossroads: Between the Bologna Process and National Reforms, Dordrecht: Springer, pp. 553-572.

Harman, G. and Harman, K. (2003) 'Institutional mergers in higher education: lessons from international experience', Tertiary Education and Management 9(1): 2944.

Hay, H. R., Fourie, M. and Hay, J. F. (2001) 'Are institutional combinations, mergers or amalgamation the answer? An investigation into staff perceptions', South African Journal of Higher Education 15(1): 100-108.

Kyvik, S. (2002) 'The merger of non-university colleges in Norway', Higher Education 44(1): 53-72.

Livio, H.-L. and Tomperi, H. (2011) 'Making sense of academic leadership', Engage $27,1-4$.

Mao, Y., Du, Y. and Lia, J. (2009) 'The effects of university mergers in China since 1990s', International Journal of Educational Management 23(1): 19-33.

Mathieson, S. (2012) 'Disciplinary cultures of teaching and learning as socially situated practice: rethinking the space between social constructivism and epistemological essentialism from the South African experience', Higher Education 63(5): 549564.

Mathisen, E.H. and Pinheiro, R. (2016) 'The Anatomy of a Merger Process in the Greater Oslo Region', in R. Pinheiro, L.Geschwind and T.Aarrevaara (eds.) Mergers in Higher Education - The Experience from Northern Europe. Higher Education Dynamics, vol. 46. Springer, pp. 91-106.

Melin, G. (2015) 'University Merger Processes', in R. Pritchard, M. Klumpp and U. Teichler (eds.) Diversity and Excellence in Higher Education - Can the Challenges be Reconciled, Rotterdam: Sense Publishers, pp. 31-52.

Opetusministeriö. (2008) Korkeakoulujen rakenteellisen kehittämisen suuntaviivat vuosille 2008-2011. [Guidelines for the Structural Development of Higher Education Institutions for 2008-2011]. Electronic publication in Finnish.

Pinheiro, R. and Stensaker, B. (2014) 'Designing the entrepreneurial university: The interpretation of a global idea', Public Organization Review 14(4): 497-516. 
Puusa, A. and Kekäle, J. (2015) 'Feelings over facts - a university merger brings organizational identity to the forefront', Journal of Higher Education Policy and Management 37(4): 432-446.

Stein, R.B. and Short, P.M. (2001) 'Collaboration in delivering higher education programs: Barriers and challenges', The Review of Higher Education 24(4): 417-435.

Stensaker, B., Persson, M. and Pinheiro, R. (2016) 'When mergers fail: a case study on the critical role of external stakeholders in merger initiatives', European Journal of Higher Education 6(1): 56-70.

Tienari, J., Aula, H-M. and Aarrevaara, T. (2016) 'Built to be excellent? The Aalto University merger in Finland', European Journal of Higher Education 6(1): 2540.

Ursin, J. (2017) 'Transforming Finnish higher education: Institutional mergers and conflicting academic identities', Revista de Investigación Educativa 35(2): 307316.

Ursin, J., Aittola, H., Henderson, C. and Välimaa, J. (2010) 'Is education getting lost in university mergers?', Tertiary Education and Management 16(4): 327-340.

Vartiainen, P. (2017) 'Campus-based tensions in the structural development of a newly merged university: the case of the University of Eastern Finland', Tertiary Education and Management 23(1): 53-68.

Välimaa, J. (2012) The Corporatization of National Universities in Finland, in B. Pusser, K. Kempner, S. Marginson and I. Ordorika (eds.) Universities and the Public Sphere. Knowledge Creation and State Building in the Era of Globalization, New York, London: Routledge, pp. 101-120.

Williams, J. (2017) Collaboration, alliance, and merger among higher education institutions. OECD Education Working Paper No. 160.

Ylijoki, O-H. and Ursin, J. (2013) 'The construction of academic identity in the changes of Finnish higher education', Studies in Higher Education 38(8): 1135-1149. 